\title{
Micellar LC Separation of Sesquiterpenic Acids and Their Determination in Valeriana officinalis L. Root and Extracts
}

\author{
Artem U. Kulikov \\ Laboratory of Pharmacopoeial Analysis, Scientific and Expert Pharmacopoeial Centre, Astronomicheskaya Street 33, \\ Kharkov 61085, Ukraine \\ Correspondence should be addressed to Artem U. Kulikov, kulikov@phukr.kharkov.ua
}

Received 28 November 2011; Accepted 17 January 2012

Academic Editor: Samuel Carda-Broch

Copyright ( 92012 Artem U. Kulikov. This is an open access article distributed under the Creative Commons Attribution License, which permits unrestricted use, distribution, and reproduction in any medium, provided the original work is properly cited.

A simple micellar liquid chromatography (MLC) method was developed and validated according to ICH Guidelines for the determination of sesquiterpenic acids (valerenic, hydroxyvalerenic, and acetoxyvalerenic acids) in root and rhizome extract from Valeriana officinalis L. and valerian dry hydroalcoholic extract. Samples were analyzed on Nucleosil C18 column $(150 \mathrm{~mm} \times 4.6 \mathrm{~mm}$, $5 \mu \mathrm{m}$ ) using an isocratic mobile phase which consisted of Brij 35 (5\% (w/v) aqueous solution; $\mathrm{pH} 2.3 \pm 0.1$ by phosphoric acid) and 1-butanol $(6 \%(\mathrm{v} / \mathrm{v}))$; UV detection was at $220 \mathrm{~nm}$. Micellar mobile phase using allows to fully separate valerenic acids within 25 minutes. Linearity for hydroxyvalerenic, acetoxyvalerenic, and valerenic acids was 1.9-27.9, 4.2-63.0, and 6.1-91·3 $\mu \mathrm{g} . \mathrm{mL}^{-1}$, and limit of detection was $0.14,0.037$, and $0.09 \mu \mathrm{g} \cdot \mathrm{mL}^{-1}$, respectively. Intraday and interday precisions were not less than $2 \%$ for all investigated compounds. The proposed method was found to be reproducible and convenient for quantitative analysis of sesquiterpenic acids in valerian root and related preparations.

\section{Introduction}

Valeriana officinalis L. is the most common species of the genus Valeriana that is used for its medicinal properties [1]. The root and rhizome of the valerian plant is used medicinally for its sedative properties with indications including nervous tension, insomnia, anxiety, and stress. Valerian is also considered to have antispasmodic, anticonvulsant, and antidepressant effects.

The roots and rhizomes of Valeriana officinalis contain two main groups of constituents: sesquiterpenes of the volatile oil (valerenic acid and its derivatives, valeranone, valeranal, and kessyl esters) and valepotriates (valtrate, didrovaltrate, acevaltrate, and isovaleroxyhydroxyvaltrate), in addition to other constituents such as flavonoids, triterpenes, lignans, and alkaloids $[2,3]$.

Valerian is available in a variety of formulations, including tablets, capsules, liquid, teas, and tinctures. Products may contain whole herb and/or a proprietary blend or may also be combined with other herbal supplements (e.g., lemon balm, hops, kava, St. John's worth, etc.). Valerian root and some commercial products (drugs) are standardized according to the content of valerenic acid, but concentrations vary among products.

Valerenic acids are sesquiterpenes based on the dual ring valerane structure with the main representatives being valerenic acid ((2E)-3-[(4S,7R,7aR)-3,7-dimethyl-2, 4,5,6,7,7a-hexahydro-1H-inden-4-yl]-2-methylacrylic acid; $\mathrm{C}_{15} \mathrm{H}_{22} \mathrm{O}_{2}$ ), acetoxyvalerenic acid, and hydroxyvalerenic acid. Chemical structures of these acids are presented in Figure 1.

Several methods, adopting different analytical techniques, have been reported to analyze sesquiterpenic acids: TLC [4-6], SFC [7], and HPLC-UV, which is the most commonly used method.

Bos et al. $[8,9]$ simultaneously analyzed valepotriates (valtrate, isovaltrate, acevaltrate, and didrovaltrate), valerenic acids (valerenic, hydroxyvalerenic, and acetoxyvalerenic), baldrinal and homobaldrinal by HPLC-DAD using LiChrospher 100 RP-18 column, and gradient elution of acetonitrile-water mobile phases. Total analysis time was 30 min.

Gobbeto and Lolla [10] proposed the HPLC method for the determination of valerenic acids in valerian extracts using Hypersil ODS column and gradient elution with acetonitrile 


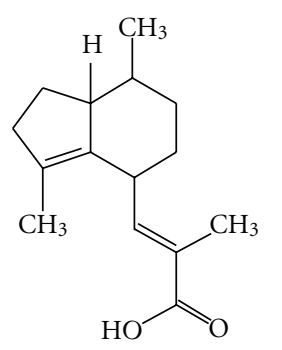

$$
\operatorname{lgPow}=5.13
$$$$
\mathrm{p} K_{a}=4.84
$$

Valerenic acid<smiles>CC1=C2C(/C=C(\C)C(=O)O)CCC(C)C2(O)CC1</smiles>

$\lg$ Pow $=3.29$

$\mathrm{p} K_{a} 1=4.84$

$\mathrm{p} K_{a} 2=14.65$

Hydroxyvalerenic acid<smiles>CC(=O)OC12CCC(C)=C1C(/C=C(\C)C(=O)O)CCC2C</smiles>

$\operatorname{lgPow}=4.11$

$\mathrm{p} K_{a}=4.84$

Acetoxyvalerenic acid

FIGURE 1: Sesquiterpenic acids chemical structures, calculated values of logarithm of partition constant in 1-octanol-water system lgPow, and protonization constants $\left(\mathrm{p} K_{a}\right)$.

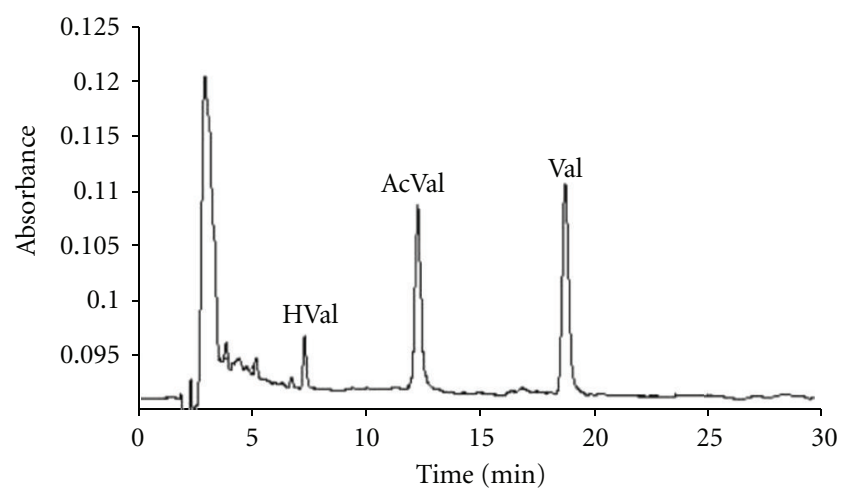

FIGURE 2: Chromatogram of sesquiterpenic acids separation obtained by approved RP HPLC method. Kromasil C18 chromatographic column; linear gradient elution with $5 \mathrm{~g} \cdot \mathrm{L}^{-1}$ aqueous $\mathrm{H}_{3} \mathrm{PO}_{4}$-acetonitrile mobile phases; flow rate $1.5 \mathrm{~mL} \cdot \mathrm{min}^{-1}$; UV $220 \mathrm{~nm}$. $\mathrm{HVal}$ : hydroxyvalerenic acid, AcVal: acetoxyvalerenic acid, and Val: valerenic acid.

containing $0.1 \%$ phosphoric acid-acetonitrile mobile phase; UV detection at $220 \mathrm{~nm}$; analysis time was $40 \mathrm{~min}$.

Bicchi et al. [7] developed supercritical fluid chromatography method with UV detection for the determination of valerenic acids and valepotriates in valerian extracts (analysis time is $20 \mathrm{~min}$ ) and compared results, obtained during valerian extracts analysis that were determined by SFC and HPLC methods.

European Pharmacopoeia [11] for the analysis of valerenic acids in valerian root end extracts proposed HPLC-UV method with C18 column using an acetonitrile-phosphoric acid aqueous solution gradient elution. Detection at $220 \mathrm{~nm}$ and total analysis time is about $30 \mathrm{~min}$ (Figure 2).

As we can see, all LC methods required gradient elution techniques for separation and assay of sesquiterpenic acids in raw plant materials and drugs.

It was already described that micellar liquid chromatography (MLC) is an alternative for RP HPLC method $[12,13]$. MLC is successfully applied to the analysis of drugs $[14,15]$ and biological fluids [16], and nowadays this method is widely used for the analysis of raw plant materials and plant containing drugs $[17,18]$. One of MLC advantages that made this method preferable to HPLC is the simultaneous separa- tion of both ionic and nonionic compounds, substances with different hydrophobicity without needing gradient elution.

The aim of this work is an investigation of possibility to separate valerenic acids using MLC method, to validate method according ICH validation requirements (specificity, accuracy, precision, and linearity), and an application of the developed method for the rapid sesquiterpenic acid analysis in raw materials (roots and rhizomes of Valeriana officinalis) and valerian dry extracts.

\section{Experimental}

2.1. Reagents and Materials. Acetoxyvalerenic acid (AcVal), hydroxyvalerenic acid (HVal), and valerenic acid (Val) were isolated from Valeriana officinalis L. in Plant Material Department of the Scientific and Expert Pharmacopoeial Centre, Ukraine, as described in [19]. Chemical structure was confirmed using IR, ${ }^{1} \mathrm{H}$, and ${ }^{13} \mathrm{C}$ NMR spectra (in the State Scientific Institution "Institute for Single Crystals" of the National Academy of Sciences of Ukraine). Chromatographic purity was determined by RP HPLC method [11]; those were more than $98.5 \%$ for all cases. 
Valerian standardized dry extract EP CRS $(0.38 \%$ $\mathrm{C}_{15} \mathrm{H}_{22} \mathrm{O}_{2}$ (valerenic acid) was from European Pharmacopoeia (Strasbourg, France).

1-butanol (1-BuOH), concentrated phosphoric acid, polyethylene glycol dodecyl ether (Brij 35), methanol (HPLC grade), and other chemicals were purchased from Fluka Chemie (Buchs, Switzerland). Double-distilled water was used in all experiments.

Fragmented underground parts of Valeriana officinalis L. were from "Sumyfitofarmacia Ltd," Ukraine; valerian dry extracts were from "AIM Ltd," Ukraine.

2.2. Apparatus. The chromatographic measurements were carried out with Hewlett Packard equipment (Agilent Technologies, Waldbronn, Germany) consisting of a Series 1050 pump, a Series 1050 spectrophotometric detector with the variable wavelength, and a Series 3395 integrator. The analytical column was the reversed-phase Nucleosil C18 $(150 \mathrm{~mm}$ $\times 4.6 \mathrm{~mm}, 5 \mu \mathrm{m}$, Macherey-Nagel, Germany). The $\mathrm{pH}$ values were determined with a Beckman $\Phi-200 \mathrm{pH}$ meter (Beckman Instruments, Fullerton, CA, USA) and Paratrode electrode (Metrohm AG, Herisau, Switzerland).

For the determination of peak purity, the Waters 2695 Separation Module (Waters, Milford, MA, USA) with Waters 996 Photodiode Array Detector (Waters) was used.

2.3. Standard Preparation. A stock standard solution was prepared by weighting an amount of hydroxyvalerenic acid, acetoxyvalerenic acid, and valerenic acid in a $100 \mathrm{~mL}$ volumetric flask, dissolving it in methanol to obtain concentrations of investigated compounds $0.0465 \mathrm{mg} \cdot \mathrm{mL}^{-1}$, $0.105 \mathrm{mg} \cdot \mathrm{mL}^{-1}$, and $0.152 \mathrm{mg} \cdot \mathrm{mL}^{-1}$, respectively. The solution was stored in a dark place at the temperature $5^{\circ} \mathrm{C}$ during 7 days.

Working standard solutions (used for linearity evaluation, evaluation of precision, repeatability, and accuracy of the MLC method) were prepared by dilution of the stock standard solution with a micellar mobile phase to obtain solutions with different concentrations within the range of interest.

\subsection{Sample Preparation}

Valerian Root. Extract $1.50 \mathrm{~g}$ of powdered underground parts of Valeriana officinalis ( $1 \mathrm{~mm}$ ) with $20 \mathrm{~mL}$ of methanol and heat on a water bath under a reflux condenser for $30 \mathrm{~min}$. Allow to cool and filter through a paper filter into a $50 \mathrm{~mL}$ volumetric flask. Add another $20 \mathrm{~mL}$ of methanol, heat on a water bath under a reflux condenser for $15 \mathrm{~min}$, cool, filter into the same $50 \mathrm{~mL}$ volumetric flask, and dilute to $50.0 \mathrm{~mL}$ with methanol [11].

Valerian Dry Extract. Place about $0.5 \mathrm{~g}$ of valerian dry extract in a $25 \mathrm{~mL}$ volumetric flask, add $15 \mathrm{~mL}$ methanol, mix, and sonicate during $10 \mathrm{~min}$. Then the solution is diluted to $25.0 \mathrm{~mL}$ with methanol and mix [11].

All samples must be filtered through a $45 \mu \mathrm{m}$ HPLC filter (DynaCard HPLC filter, Microgon, USA) before analysis.
2.5. Chromatographic Separation. A 5\% (w/v) aqueous solution of Brij 35 with $6 \%(\mathrm{v} / \mathrm{v})$ of 1-butanol, adjusted to $\mathrm{pH}$ $2.3 \pm 0.1$ by phosphoric acid, was prepared and used as mobile phase. The flow rate was set at $1.0 \mathrm{~mL} \cdot \mathrm{min}^{-1}$, and the injection volume was $10 \mu \mathrm{L}$. The chromatographic runs were carried out at $40.0 \pm 0.1^{\circ} \mathrm{C}$. Detection wavelength was chosen at $220 \mathrm{~nm}$.

2.6. Data Sources, Software, and Processing. The statistical analyses were performed with Microsoft Excel (2007, Microsoft Corporation, http://office.microsoft.com/). The values of $\operatorname{lgPow}$ and $\mathrm{p} K_{a}$ were calculated using ACDLabs 10.0 (2010, http://www.ACDLabs.com/) and ChemBioDraw 11.0 (2010, Cambridgesoft, http://www.cambridgesoft.com/).

\section{Results and Discussion}

Nonionic surfactants, unfortunately, are not widely used for micellar liquid chromatographic separation of compounds with different hydrophobicity. It was not found any recommendation in the literature about an approximate nonionic surfactant concentration, which is required for different hydrophobicity substances separation, as described for sodium dodecyl sulfate as micellar-forming agent [12]. In [20-22] it was found that concentration of nonionic surfactants to be micellar eluents should be sufficiently large-5$10 \%(\mathrm{w} / \mathrm{v})$.

Figure 1 provides the chemical structures and some physical-chemical characteristics of investigated compounds: hydrophobicity as lgPow (logarithms of partition constant in 1-octanol-water system) and pKa values. Hydrophobicity of compounds is not quite different and ranges from 3 for hydroxyvalerenic acid to 5 for valerenic acid. Wang et al. [20] separated quinazoline derivatives with hydrophobicity 2-4 using $0.06 \mathrm{M}$ Brij $35(6 \% \mathrm{w} / \mathrm{v})$ as a micellar mobile phase.

Preliminary experiment for valerenic acids separation showed that its retention in approximately $0.06 \mathrm{M}$ Brij 35 mobile phase was about $75 \mathrm{~min}$, and peaks asymmetries of investigated compounds were high.

According to $\mathrm{p} K_{a}$ values, at $\mathrm{pH}$ value below 4 , the predominant form of compounds in solution is molecular forms-all ionizable groups are fully protonated, and at $\mathrm{pH}$, above 6 compounds are negatively charged. A mobile phase for acid separation should be acidified. Preliminary experiments have shown that when acidified $0.06 \mathrm{M}$ Brij 35 containing micellar mobile phase used for separation of the investigated compounds, peak symmetry is lower than 2 ; it is appropriate to the assay determination.

It was investigated retention time, peak symmetry, and resolution for different micellar mobile phases to choose an optimal micellar mobile phase composition. Brij 35 concentrations in mobile phases were varying from $2 \%$ to $8 \%$ $(\mathrm{w} / \mathrm{v})$ with a step of $1 \%$, and micellar mobile phase organic modifier (1-bithanol) was varying from $1 \%$ to $10 \%(\mathrm{v} / \mathrm{v})$ with the same step. The mobile phase $\mathrm{pH}$ in all cases was about $2.3 \pm 0.1$.

The optimization procedure $[23,24]$ that was used for choosing the optimal mobile phase composition showed that 

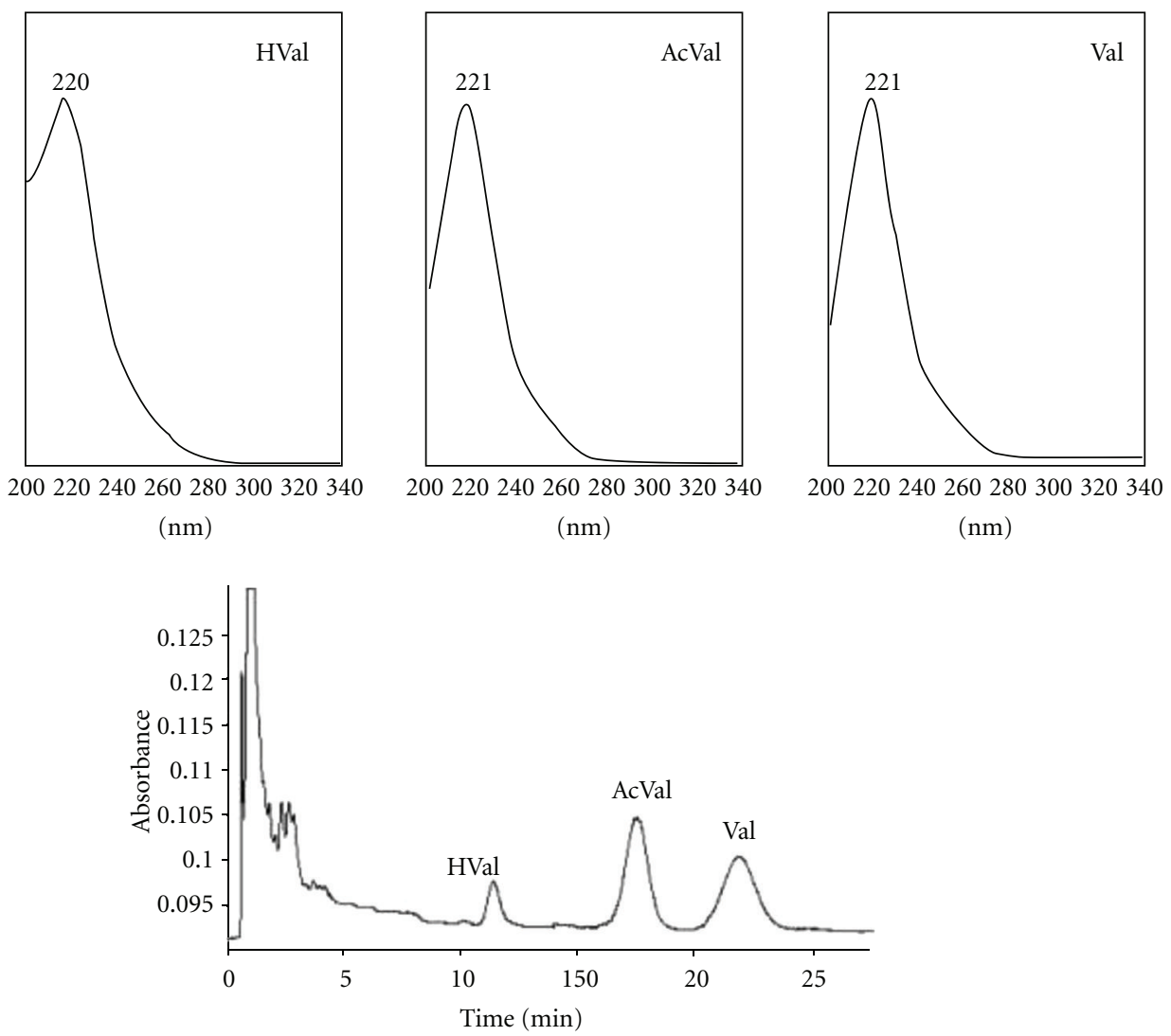

Figure 3: Micellar LC separation of sesquiterpenic acids during selectivity determination. HVal: hydroxyvalerenic acid, AcVal: acetoxyvalerenic acid, and Val: valerenic acid.

for all micellar mobile phases were obtained good chromatographic characteristics: sesquiterpenic acid resolution was more than 1.5, and peak symmetry was 1.5-2. Lowest retention time $(12 \mathrm{~min})$ was obtained when $8 \%(\mathrm{w} / \mathrm{v})$ of Brij 35 and $10 \%(\mathrm{v} / \mathrm{v})$ of $1-\mathrm{BuOH}$ as micellar mobile phase components were used. Unfortunately, this micellar mobile phase has high viscosity, and column input pressure was unacceptable: $350-370$ bar whereas chromatograph pump upper pressure limit is 400 bar. When a mobile phase with low viscosity (2\% (w/v) of Brij 35 and $1 \%(\mathrm{v} / \mathrm{v})$ of $1-\mathrm{BuOH})$ was used for sesquiterpenic acids separation, total analysis time was about $90 \mathrm{~min}$.

Optimum between micellar mobile phase viscosity (relatively low viscosity) and analysis time (till $25 \mathrm{~min}$ ) was found, when Brij 35 concentration of $5 \%(\mathrm{w} / \mathrm{v})$ and $1-\mathrm{BuOH}$ volume fraction of $6 \%(\mathrm{v} / \mathrm{v})$ were chosen.

In addition, the efficiency of the separation and peak asymmetry can be improved by using high temperatures due to faster mass transfer of solutes between mobile and stationary phases [15], and for reducing of mobile phase viscosity. A column temperature $40^{\circ} \mathrm{C}$ was chosen, because higher temperature $\left(50\right.$ and $\left.60^{\circ} \mathrm{C}\right)$ had not exerted significant influence on the chromatographic behavior of investigated compounds.

3.1. Validation of the MLC Method. The procedures and parameters used for the validation of the chromatographic method developed in this study are those described in [25, 26].

3.1.1. Specificity (Selectivity). The specificity of the method was determined by analyzing valerian-standardized dry extract EP CRS and methanolic extract of valerian root. Methanolic extract was analyzed without and with addition of investigated compounds; increasing peak areas indicate the presence of valerenic acids in the chromatogram. Selectivity of the MLC method was assessed by the comparison of the spectrum extracted from the chromatogram of valerianstandardized dry extract and methanolic extract obtained using photodiode array detector; peak purity was also determined.

Figure 3 shows a chromatogram and UV spectra obtained for valerian-standardized dry extract, which contains (see Figure 2) hydroxyvalerenic, acetoxyvalerenic, and valerenic acids. The same spectra were obtained for valerian methanolic extract. The peaks purity was more than $98.5 \%$ in all cases.

3.1.2. Linearity. A linear plot was obtained from six different concentrations of working standard solutions using four replicate injections $[25,26]$. The regression line was calculated as $Y=a+b C$, where $C$ was the analyte concentration 
TABLE 1: Characteristic parameters of the calibration equations for the proposed MLC method for sesquiterpenic acids determination.

\begin{tabular}{|c|c|c|c|}
\hline Parameters & Hydroxyvalerenic acid & Acetoxyvalerenic acid & Valerenic acid \\
\hline $\begin{array}{l}\text { Calibration range } \\
\left(\mu \mathrm{g} \cdot \mathrm{mL}^{-1}\right)\end{array}$ & $1.9-27.9$ & $4.2-63.0$ & $6.1-91.2$ \\
\hline Detection limit $\left(\mu \mathrm{g} \cdot \mathrm{mL}^{-1}\right)$ & 0.037 & 0.09 & 0.14 \\
\hline $\begin{array}{l}\text { Quantitation limit } \\
\left(\mu \mathrm{g} \cdot \mathrm{mL}^{-1}\right)\end{array}$ & 0.11 & 0.27 & 0.42 \\
\hline \multicolumn{4}{|c|}{ Parameters of regression equation $Y=a+b \cdot C$, where $C$ is the concentration of compound in $\mu \mathrm{g} \cdot \mathrm{mL}^{-1}, Y$ is the peak area } \\
\hline Intercept $(a)$ & $-5.5 \cdot 10^{3}$ & $-7.8 \cdot 10^{4}$ & $-1.6 \cdot 10^{4}$ \\
\hline SD of the intercept $\left(S_{a}\right)$ & $0.3 \cdot 10^{3}$ & $0.6 \cdot 10^{4}$ & $0.1 \cdot 10^{4}$ \\
\hline Slope $(b)$ & $27.1 \cdot 10^{3}$ & $21.3 \cdot 10^{4}$ & $23.8 \cdot 10^{4}$ \\
\hline SD of the slope $\left(S_{b}\right)$ & $0.2 \cdot 10^{3}$ & $0.2 \cdot 10^{4}$ & $0.2 \cdot 10^{4}$ \\
\hline RSD of the slope, $\%$ & 0.74 & 0.94 & 0.84 \\
\hline Correlation coefficient $(r)$ & 0.9995 & 0.9994 & 0.9995 \\
\hline
\end{tabular}

$\left(\mu \mathrm{g} \mathrm{mL}^{-1}\right)$, and $y$ was the peak area. The calibration plot was obtained by linear least-squares regression.

Calibration parameters, such as slope, intercept, and correlation coefficient are provided in Table 1. The correlation coefficient $(r)$ was close to unity; hence, there was a linear relationship between amount of analyte and detector signal. The systematic deviations between experimental and predicted responses were not observed.

Since the coefficient of correlation is not suitable as a general acceptance criterion to the linearity performance of an analytical procedure [27], the relative standard error of slope was used as a parameter with respect to precision of the regression. This parameter should be comparable to the relative standard deviation obtained in precision studies within the given concentrations range. Relative standard error of slopes was obtained to be less than RSD of precision.

3.1.3. Limit of Detection and Quantitation. The limits of detection (LOD) and quantitation (LOQ) were calculated in accordance with the $3.3 \mathrm{~s} / \mathrm{m}$ and $10 \mathrm{~s} / \mathrm{m}$ criteria, respectively, where $s$ is the standard deviation of the peak area for the sample, and $m$ is the slope of the calibration curve, determined from linearity [25]. Both values were calculated and presented in Table 1.

3.1.4. Accuracy. The accuracy of the proposed method was tested in some ways. First, samples of known concentration (working standard solutions) were analyzed, and measured values were compared with the true value. The results obtained from determination of accuracy, expressed as percentage recovery, are summarized in Table 2. Accuracy criterion for the assay method is that the mean recovery will be $100 \pm 2 \%$ for each concentration over the investigation range [28]. The recovery of the proposed method was good.

Second, this study was performed by addition of known amounts of studied compounds to a solution of valerian dry extract (standard addition method). The resulting mixtures were analyzed by proposed MLC method, and the obtained results were compared with the expected results. The excellent recoveries of standard addition method (Table 2) suggested good accuracy of the proposed method.
Third, accuracy of MLC method was determined by comparing results obtained by proposed method with results from the validated method using reversed-phase HPLC [11]. MLC and RP-HPLC results for sesquiterpenic acids assay were compared. Statistically analysis of the results obtained for both methods using variance ratio $F$-test shows that there is no significant difference between these results. The calculated $F$ values were less than those of the theoretical values at 95\% confidence level (see data from Table 3).

3.1.5. Precision. The precision as intraday and interday reproducibility, expressed as RSD \%, was characterized by the spread of data from replicate determinations.

For the intraday reproducibility, that is, repeatability, we performed nine determinations covering the specified range of the method. Working standard solutions were analyzed (four replicates each). Interday precision of the method was checked on three different days by preparing and analyzing working standard solutions (four replicate injections) under the same conditions.

The results obtained from these analyses are listed in Table 4 as mean recovery. The table shows that there is no significant difference between assay results either within days or between days, implying that the reproducibility of MLC method was good. In all instances, the \% R.S.D. values were less than $2 \%$ — criterion for an intra-assay precision [28].

3.2. Analysis of Plant Material and Drug. Sesquiterpenic acids (valerenic, acetoxyvalerenic, and hydroxyvalerenic acids) were quantified using developed MLC method in the valerian root and rhizomes and valerian dry extract (chromatograms of investigated compounds are presented in Figure 4). Fragmented underground parts of Valeriana officinalis L. cultivated in 2008-2011 years were from "Sumyfitofarmacia Ltd," Ukraine; valerian dry hydroalcoholic extracts obtained from above-mentioned valerian root were from "AIM Ltd," Ukraine.

The percentage of valerenic acid, acetoxyvalerenic acid, and hydroxyvalerenic acid, in root and rhizomes was, according to [11] not less than $0.17 \%$ of sesquiterpenic acids expressed as valerenic acid, calculated with the reference to 
TABLE 2: Accuracy results of MLC method: analysis of sesquiterpenic acid mixtures and standard addition technique.

\begin{tabular}{|c|c|c|c|c|c|c|c|c|}
\hline \multirow{2}{*}{ Compound } & \multirow{2}{*}{$\begin{array}{c}\text { Added } \\
\left(\mu \mathrm{g} \cdot \mathrm{mL}^{-1}\right)\end{array}$} & \multirow{2}{*}{$\begin{array}{l}\text { As found* } \\
\left(\mu \mathrm{g} \cdot \mathrm{mL}^{-1}\right)\end{array}$} & \multirow{2}{*}{ \% Recovery } & \multirow{2}{*}{$\Delta$} & \multirow{2}{*}{ Added, $\mu \mathrm{g} \cdot \mathrm{mL}^{-1}$} & \multicolumn{2}{|c|}{ As found ${ }^{*}, \mu \mathrm{g} \cdot \mathrm{mL}^{-1}$} & \multirow{2}{*}{$\begin{array}{c}\text { Recovery } \\
\%\end{array}$} \\
\hline & & & & & & with addition & $\begin{array}{l}\text { without } \\
\text { addition }\end{array}$ & \\
\hline \multirow{5}{*}{ Hydroxyvalerenic acid } & 1.90 & 1.88 & 99.0 & -1.0 & 0 & - & 2.10 & \\
\hline & 9.30 & 9.25 & 99.5 & -0.5 & 1.90 & 4.20 & 2.20 & 104.8 \\
\hline & 27.9 & 27.8 & 99.6 & -0.4 & 5.60 & 7.74 & 2.14 & 102.1 \\
\hline & & & & & 9.3 & 11.4 & 2.13 & 101.7 \\
\hline & \multicolumn{2}{|c|}{ Mean, \%R.S.D. } & $99.4,0.8$ & & & & Mean, \% & 102.9 \\
\hline \multirow{5}{*}{ Acetoxyvalerenic acid } & 4.20 & 4.19 & 99.8 & -0.2 & 0 & - & 33.4 & \\
\hline & 21.0 & 20.85 & 99.3 & -0.7 & 12.6 & 46.3 & 33.7 & 102.1 \\
\hline & 63.0 & 63.1 & 100.1 & +0.1 & 21.0 & 54.2 & 33.2 & 99.4 \\
\hline & & & & & 29.4 & 63.5 & 34.1 & 102.1 \\
\hline & \multicolumn{2}{|c|}{ Mean, \%R.S.D. } & $99.7,1.1$ & & & & Mean, \% & 101.2 \\
\hline \multirow{5}{*}{ Valerenic acid } & 6.10 & 6.07 & 99.5 & -0.5 & 0 & - & 50.7 & \\
\hline & 30.4 & 30.5 & 100.3 & +0.3 & 18.2 & 69.4 & 51.2 & 101.0 \\
\hline & 91.2 & 91.4 & 100.2 & +0.2 & 30.4 & 80.7 & 50.3 & 99.2 \\
\hline & & & & & 42.6 & 93.6 & 51.0 & 100.6 \\
\hline & \multicolumn{2}{|c|}{ Mean, \%R.S.D. } & $100.0,1.1$ & & & & Mean, \% & 100.3 \\
\hline
\end{tabular}

${ }^{*}$ Mean value of the four determinations.

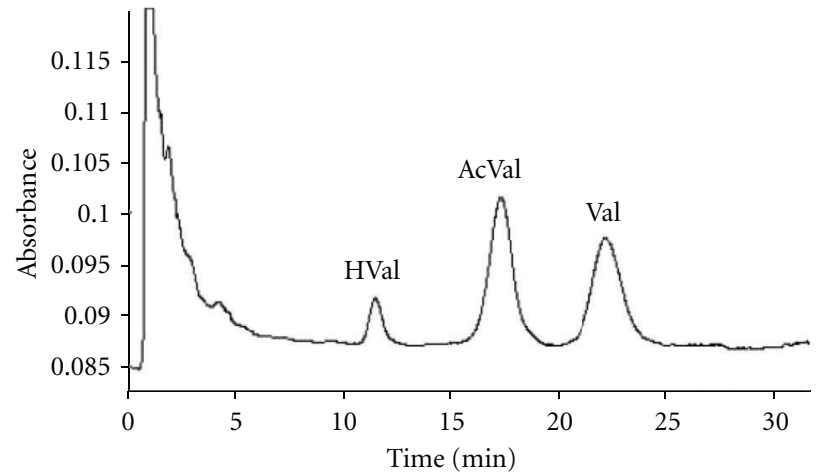

(a)

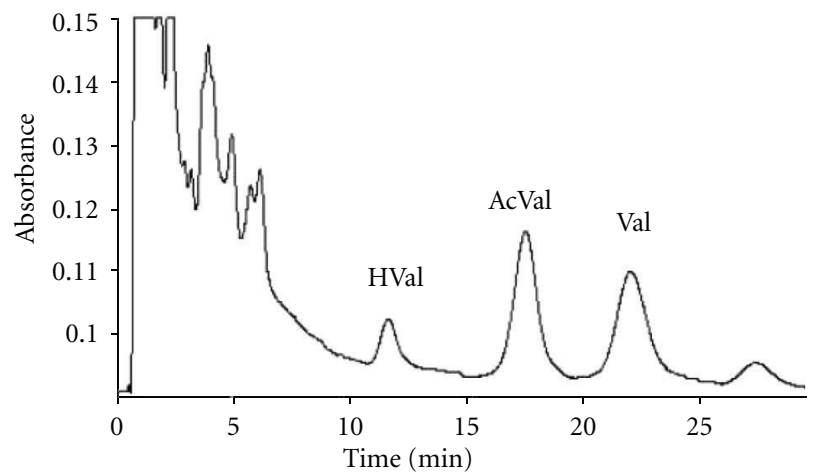

(b)

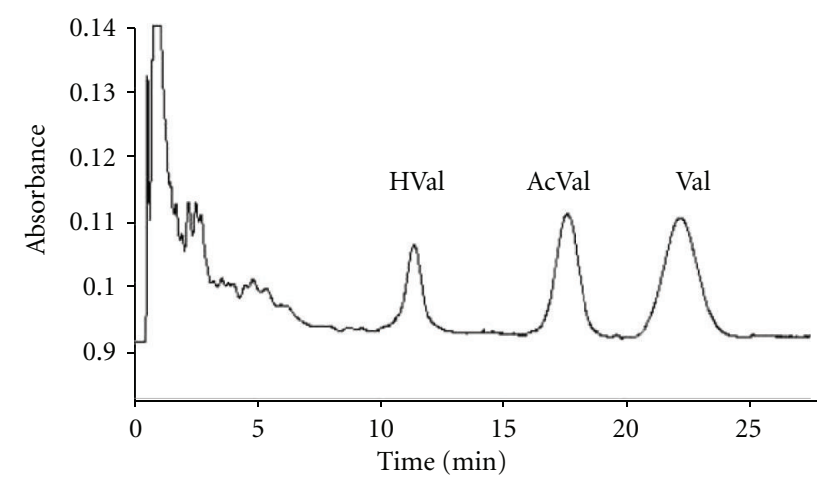

(c)

Figure 4: Chromatograms obtained during Valeriana officinalis L. root and extract analysis. HVal: hydroxyvalerenic acid, AcVal: acetoxyvalerenic acid, and Val: valerenic acid. (a) valerenic acids standard solution; (b) methanolic extract of Valeriana officinalis L. root and rhizome; (c) chromatogram of valerian hydroalcoholic dry extract. 
TABLE 3: Results from sesquiterpenic acids assay in various samples using RP-HPLC and MLC methods and verification of the variance of significance between two methods.

\begin{tabular}{|c|c|c|c|c|c|c|c|c|c|c|c|c|c|c|}
\hline \multicolumn{4}{|c|}{ MLC* } & \multicolumn{4}{|c|}{ HPLC* } & \multicolumn{4}{|c|}{$\Delta$} & \multicolumn{3}{|c|}{ Calculated $F$ values** } \\
\hline HVal, $\%$ & AcVal, \% & Val, \% & Sum, \% & HVal, \% & AcVal, \% & Val, \% & Sum, \% & HVal, \% & AcVal, \% & Val, \% & Sum, \% & HVal & AcVal & Val \\
\hline \multicolumn{15}{|c|}{ Valerian root and rhizome (3 samples) } \\
\hline 0.005 & 0.073 & 0.088 & 0.166 & 0.006 & 0.070 & 0.087 & 0.163 & -0.001 & -0.003 & +0.001 & +0.003 & 3.152 & 4.261 & 2.154 \\
\hline 0.001 & 0.071 & 0.084 & 0.156 & 0.001 & 0.069 & 0.082 & 0.152 & 0 & +0.002 & +0.002 & +0.004 & 1.555 & 3.644 & 2.233 \\
\hline 0.002 & 0.082 & 0.098 & 0.182 & 0.001 & 0.085 & 0.099 & 0.185 & +0.001 & -0.003 & -0.001 & -0.003 & 4.176 & 3.954 & 3.771 \\
\hline \multicolumn{15}{|c|}{ Valerian dry extract (3 samples) } \\
\hline 0.031 & 0.142 & 0.178 & 0.351 & 0.033 & 0.145 & 0.177 & 0.355 & -0.002 & -0.003 & +0.001 & -0.004 & 3.244 & 1.547 & 3.334 \\
\hline 0.045 & 0.133 & 0.201 & 0.379 & 0.047 & 0.132 & 0.204 & 0.383 & +0.002 & +0.001 & -0.003 & -0.004 & 3.672 & 3.674 & 1.780 \\
\hline 0.028 & 0.186 & 0.214 & 0.428 & 0.030 & 0.188 & 0.213 & 0.431 & -0.002 & -0.002 & +0.001 & -0.003 & 2.966 & 2.425 & 2.655 \\
\hline
\end{tabular}

HVal: hydroxyvalerenic acid, AcVal: acetoxyvalerenic acid, Val: valerenic acid, and Sum: total contents of valerenic acids.

* Mean value of the four determinations

** Tabulated $F$ value is 6.38 .

TABLE 4: Intraday and inter-day precision data.

\begin{tabular}{lccr}
\hline Analyte & Target concentration $(100 \%), \mu \mathrm{g} / \mathrm{mL}$ & Inter-day variation*(\% \pm R.S.D) & Inter-day variation $(\% \pm$ R.S.D) \\
\hline \multirow{3}{*}{ Hydroxyvalerenic acid } & 1.90 & $101.3 \pm 1.1$ & $101.7 \pm 1.8$ \\
& 9.30 & $100.9 \pm 0.9$ & $100.3 \pm 1.1$ \\
& 27.9 & $99.9 \pm 0.7$ & $100.2 \pm 0.9$ \\
Acetoxyvalerenic acid & 4.20 & $100.7 \pm 0.5$ & $100.2 \pm 1.1$ \\
& 21.0 & $100.1 \pm 0.2$ & $100.5 \pm 0.8$ \\
\hline \multirow{3}{*}{ Valerenic acid } & 63.0 & $99.8 \pm 0.3$ & $100.1 \pm 0.5$ \\
& 6.10 & $99.5 \pm 0.9$ & $100.2 \pm 1.4$ \\
& 30.4 & $100.8 \pm 1.0$ & $100.5 \pm 1.8$ \\
\hline
\end{tabular}

* Mean value of the four determinations.

the dried drugs. Ukrainian Pharmacopoeia [29] required plants that grown in Ukraine and Russia regions, sum of sesquiterpenic acids not less than $0.10 \%$ (as valerenic acid, calculated with the reference to the dried drugs).

Valerian dry hydroalcoholic extract should content minimum $0.25 \%$ of sesquiterpenic acids, expressed as valerenic acid (dry extract) [11].

Table 3 provides the results of the determination of sesquiterpenic acids in various analytical subjects, which was obtained using micellar liquid chromatographic method. As can be seen from Table 3, not all raw materials satisfied the European Pharmacopoeia [11] requirements for valerian root, but all results fulfilled requirements of Ukrainian Pharmacopoeia. All results for valerian dry extract analysis comply with requirements of European Pharmacopoeia [11].

\section{Conclusions}

A simple and reliable MLC method for the simultaneous determination of sesquiterpenic acids (valerenic, acetoxyvalerenic, and hydroxyvalerenic acids) in valerian root and rhizomes and valerian dry extract was developed. Chromatographic method with using micellar mobile phase does not require gradient elution which is widely used in reversed-phase HPLC methods. That is the main advantage of MLC that allows separating compounds with different hydrophobicity in a single run without the gradient elution.

The method was completely validated showing satisfactory data for all the parameters tested. This method is also ecofriendly for its low concentration of organic solvent, as compared to other analytical techniques.

\section{References}

[1] S. L. Plushner, "Valerian: Valeriana officinalis," American Journal of Health-System Pharmacy, vol. 57, no. 4, pp. 328-335, 2000.

[2] M. Goppel and G. Franz, "Stability control of valerian ground material and extracts: a new HPLC-method for the routine quantification of valerenic acids and lignans," Pharmazie, vol. 59, no. 6, pp. 446-452, 2004.

[3] D. Shohet, R. B. H. Wills, and D. L. Stuart, "Valepotriates and valerenic acids in commercial preparations of valerian available in Australia," Pharmazie, vol. 56, no. 11, pp. 860-863, 2001.

[4] N. Singh, A. P. Gupta, B. Singh, and V. K. Kaul, "Quantification of valerenic acid in Valeriana jatamansi and Valeriana officinalis by HPTLC," Chromatographia, vol. 63, no. 3-4, pp. 209-213, 2006.

[5] A. P. Gupta, M. M. Gupta, and S. Kumar, "Simultaneous determination of curcuminoids in Curcuma samples using high 
performance thin layer chromatography," Journal of Liquid Chromatography and Related Technologies, vol. 22, no. 10, pp. 1561-1569, 1999.

[6] N. Singh, A. P. Gupta, B. Singh, and V. K. Kaul, "Quantification of picroside-I and picroside-II in Picrorhiza kurroa by HPTLC," Journal of Liquid Chromatography and Related Technologies, vol. 28, no. 11, pp. 1679-1691, 2005.

[7] C. Bicchi, A. Binello, and P. Rubiolo, "Packed column SFC/UV versus HPLC/UV analysis of valerenic acids and valepotriates in extracts of Valeriana officinalis L.," Phytochemical Analysis, vol. 11, no. 3, pp. 179-183, 2000.

[8] R. Bos, H. J. Woerdenbag, H. Hendriks et al., "Analytical aspects of phytotherapeutic valerian preparations," Phytochemical Analysis, vol. 7, no. 3, pp. 143-151, 1996.

[9] R. Bos, H. J. Woerdenbag, F. M. S. Van Putten, H. Hendriks, and J. J. C. Scheffer, "Seasonal variation of the essential oil, valerenic acid and derivatives, and valepotriates in Valeriana officinalis roots and rhizomes, and the selection of plants suitable for phytomedicines," Planta Medica, vol. 64, no. 2, pp. 143-147, 1998.

[10] S. Gobbeto and E. Lolla, "A new HPLC method for the analysis of valerenic acids in Valeriana officinalis extracts," Fitoterapia, vol. 67, no. 2, pp. 159-162, 1996.

[11] European Pharmacopoeia, Council of Europe, Strasbourg, France, 7th edition, 2011.

[12] A. Berthod and M. C. Garcia-Alvarez-Coque, Micellar Liquid Chromatography, Marcel Dekker, New York, NY, USA, 2000.

[13] A. U. Kulikov, A. G. Verushkin, and L. P. Loginova, "Comparison of micellar and reversed-phase liquid chromatography for determination of sulfamethoxazole and trimethoprim," Chromatographia, vol. 61, no. 9-10, pp. 455-463, 2005.

[14] I. Rapado-Martínez, M. C. García-Alvarez-Coque, and R. M. Villanueva-Camañas, "Performance of micellar mobile phases in reversed-phase chromatography for the analysis of pharmaceuticals containing $\beta$-blockers and other antihypertensive drugs," Analyst, vol. 121, no. 11, pp. 1677-1682, 1996.

[15] B. L. Kolte, B. B. Raut, A. A. Deo, M. A. Bagool, and D. B. Shinde, "Simultaneous determination of metformin in its multicomponent dosage forms with glipizide and gliclazide using micellar liquid chromatography," Journal of Liquid Chromatography and Related Technologies, vol. 26, no. 7, pp. 1117-1133, 2003.

[16] D. Bose, A. Durgbanshi, S. Carda-Broch, M. Gil-Agustí, M. E. Capella-Peiró, and J. Esteve-Romero, "Direct injection analysis of epinephrine, norepinephrine, and their naturally occurring derivatives in serum by micellar liquid chromatography with electrochemical detection," Journal of Liquid Chromatography and Related Technologies, vol. 28, no. 20, pp. 3265-3281, 2005.

[17] A. U. Kulikov, M. N. Galat, and A. P. Boichenko, "Optimization of micellar LC conditions for the flavonoid separation," Chromatographia, vol. 70, no. 3-4, pp. 371-379, 2009.

[18] J. Gu, X. Zeng, B. Kong, Y. Mao, W. Liu, and W. Wei, "Rapid determination of polyphenols in tobacco by MLC," Chromatographia, vol. 71, no. 9-10, pp. 769-774, 2010.

[19] R. Bos, H. Hendriks, A. P. Bruins, J. Kloosterman, and G. Sipma, "Isolation and identification of valerenane sesquiterpenoids from Valeriana officinalis," Phytochemistry, vol. 25, no. 1, pp. 133-135, 1985.

[20] S. Wang, G. Yang, Z. Li, L. Haiyan, J. Bai, and Y. Zhang, "Micellar liquid chromatography study of quantitative retention-activity relationships for antihypertensive drugs," Chromatographia, vol. 64, no. 1-2, pp. 23-29, 2006.
[21] M. F. Borgerding, W. L. Hinze, L. D. Stafford, G. W. Fulp, and W. C. Hamlin, "Investigations of stationary phase modification by the mobile phase surfactant in micellar liquid chromatography," Analytical Chemistry, vol. 61, no. 13, pp. 1353-1358, 1989.

[22] M. F. Borgerding and W. L. Hinze, "Characterization and evaluation of the use of nonionic polyoxyethylene(23)dodecanol micellar mobile phases in reversed-phase high-performance liquid chromatography," Analytical Chemistry, vol. 57, no. 12, pp. 2183-2190, 1985.

[23] L. P. Loginova, L. V. Samokhina, A. P. Boichenko, and A. U. Kulikov, "Micellar liquid chromatography retention model based on mass-action concept of micelle formation," Journal of Chromatography A, vol. 1104, no. 1-2, pp. 190-197, 2006.

[24] A. U. Kulikov, A. P. Boichenko, and A. G. Verushkin, "Optimization of micellar LC conditions for separation of opium alkaloids and their determination in pharmaceutical preparations," Analytical Methods, vol. 3, no. 12, pp. 2749-2757, 2011.

[25] "Validation of Analytical procedures: Text and Methodology Q2(R1)," http://www.ich.org/.

[26] J. A. Adamovics, Chromatographic Analysis of Pharmaceuticals, Marcel Dekker, New York, NY, USA, 1997.

[27] J. Ermer and H. -J. Ploss, "Validation in pharmaceutical analysis-part II: central importance of precision to establish acceptance criteria and for verifying and improving the quality of analytical data," Journal of Pharmaceutical and Biomedical Analysis, vol. 37, no. 5, pp. 859-870, 2005.

[28] G. A. Shabir, "Validation of high-performance liquid chromatography methods for pharmaceutical analysis: Understanding the differences and similarities between validation requirements of the US Food and Drug Administration, the US Pharmacopeia and the International Conference on Harmonization," Journal of Chromatography A, vol. 987, no. 1-2, pp. 57-66, 2003.

[29] Ukrainian State Pharmacopoeia, REREIG, Kharkov, Ukraine, 1st edition, 2001. 


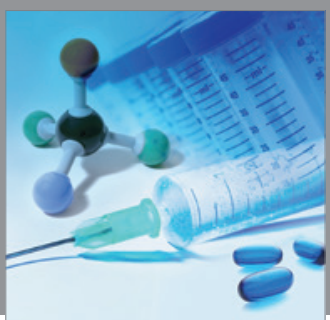

International Journal of

Medicinal Chemistry

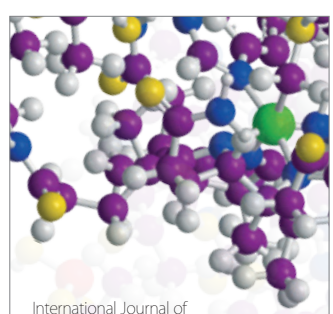

Carbohydrate Chemistry

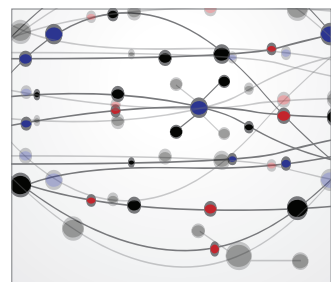

The Scientific World Journal
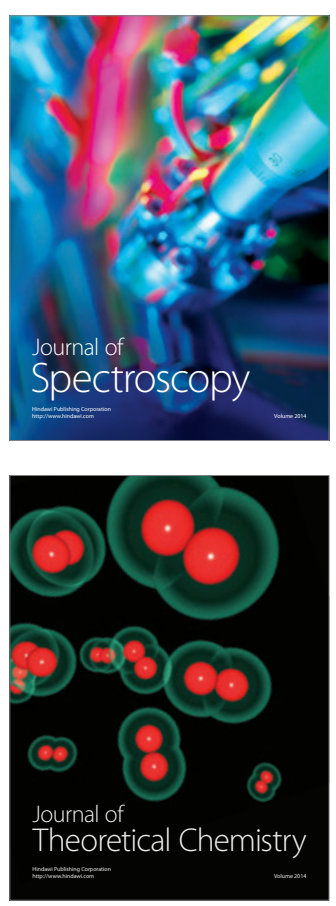
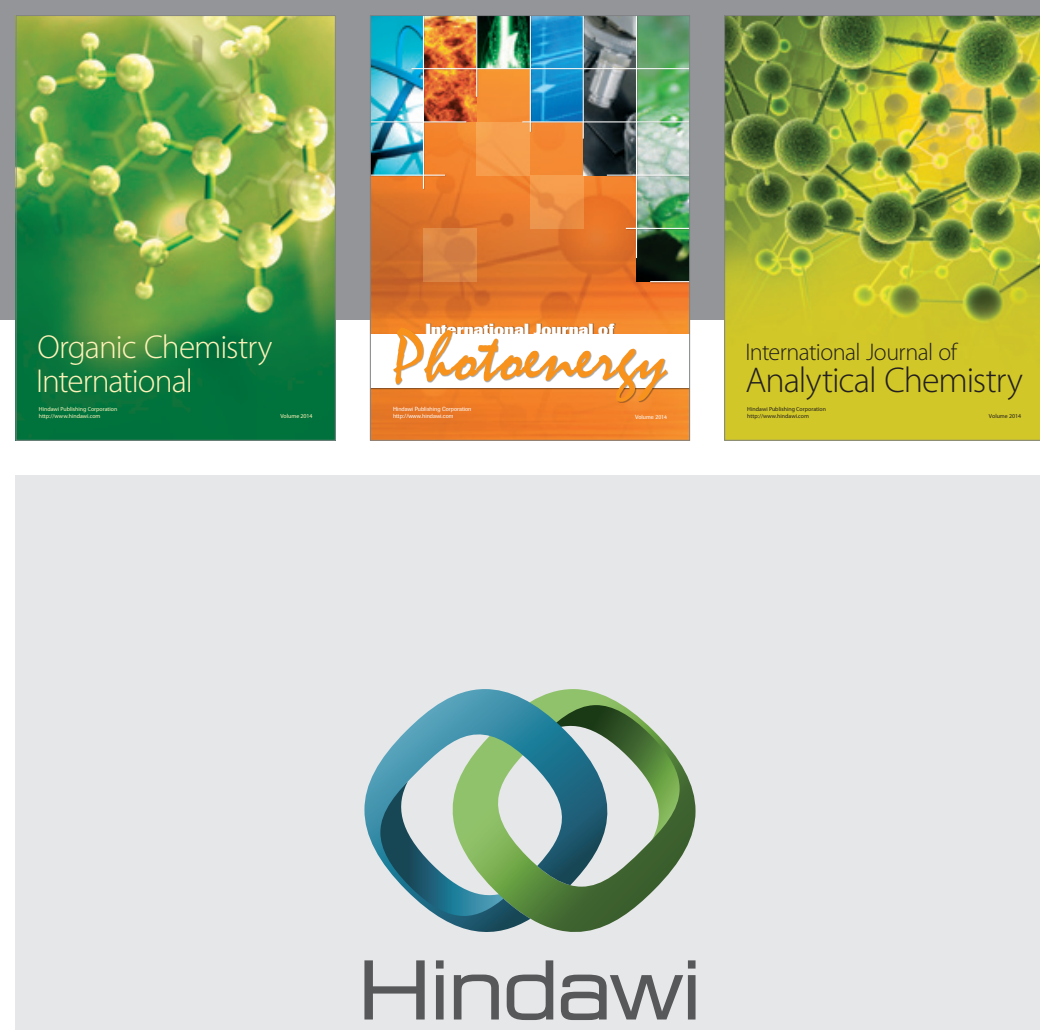

Submit your manuscripts at

http://www.hindawi.com
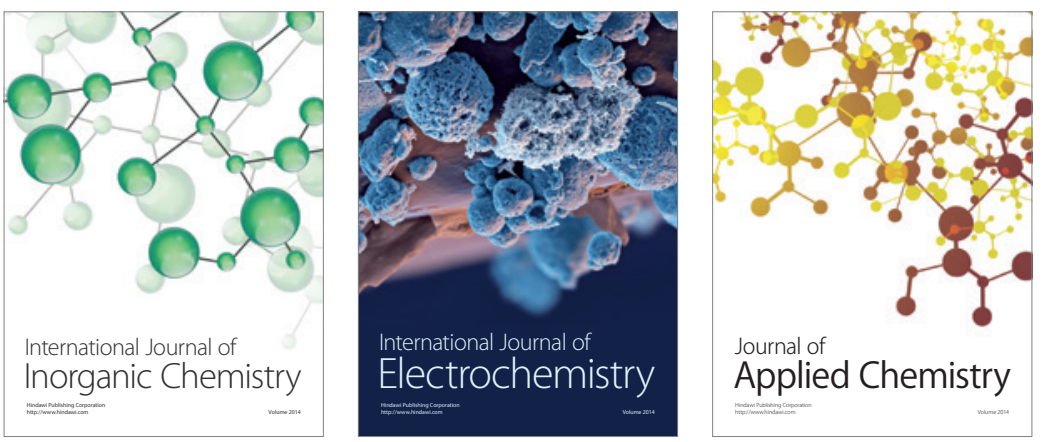

Journal of

Applied Chemistry
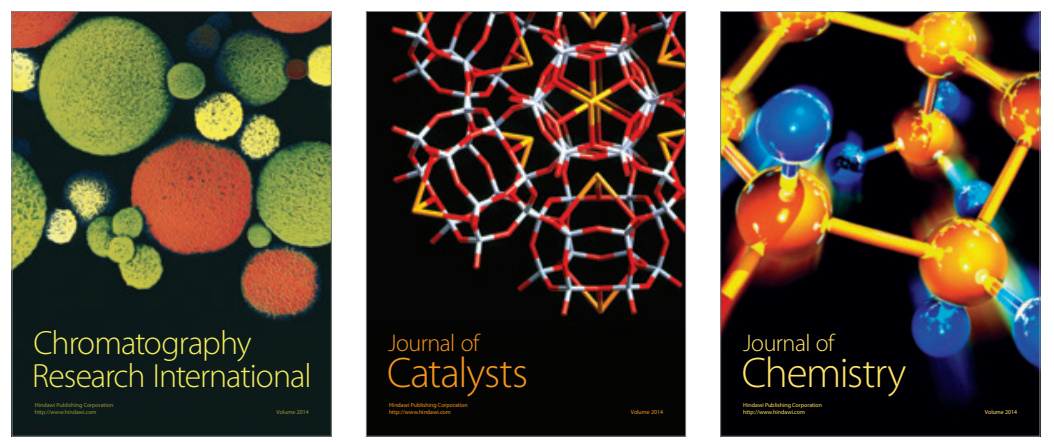
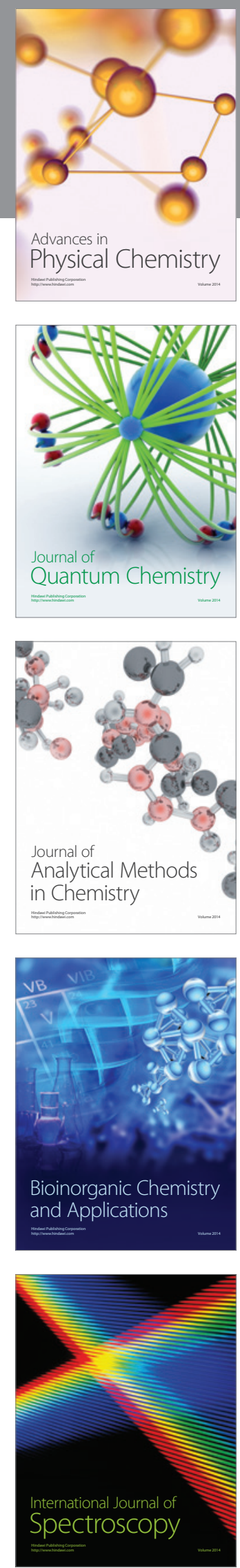